Milica M. Lukić

Univerzitet u Novom Sadu

Filozofski fakultet

Studentkinja doktorskih studija

milkenzi@gmail.com
UDK: 811.111'373.612.2:811.163.41'373.612.2

DOI: 10.19090/ZJIK.2021.125-142

originalni naučni rad

\title{
POJMOVNA METAFORA LJUBAVI U TEKSTOVIMA POP PESAMA NA SRPSKOM I ENGLESKOM
}

SAŽETAK: U ovom radu izučava se metaforička konceptualizacija LJUBAVI u tekstovima pesama četiri izvođača pop muzike (po jednog muškog i ženskog izvođača na srpskom i engleskom jeziku). Kao što ističu Lejkof i Džonson (Lakoff \& Johnson 1980/2003), pojmovne metafore odražavaju način na koji poimamo svet i izražavamo svoja mišljenja i osećanja. Cilj rada je da se istraži da li se pojmovna metafora LJUBAVI razlikuje u pesmama na srpskom i engleskom, kao i da li postoje razlike između tekstova ispevanih od strane ženskih i muških izvođača. Pokazalo se da su najfrekventniji izvorni domeni BOL/BOLEST, IGRA/KOCKA, LUDILO/MENTALNI POREMEĆAJ i PUTOVANJE. Rezultati istraživanja takođe otkrivaju da, iako nisu preterano izražene, određene razlike u konceptualizaciji LJUBAVI između dva pomenuta jezika i dva pola ipak postoje.

Ključne reči: kognitivna lingvistika, pojmovna metafora, srpski jezik, engleski jezik, konceptualizacija ljubavi

\section{UVOD}

Predmet ovog rada jeste metaforička konceptualizacija LJUBAVI u tekstovima pesama četiri izvođača pop muzike - po jednog muškog i ženskog izvođača na srpskom i engleskom jeziku. Jezik je jedan od načina za izražavanje osećanja, što često uključuje i upotrebu metafore. Prema kognitivnolingvstičkom shvatanju (Lakoff \& Johnson 1980/2003), metafora nije samo stilska figura u poeziji, nego i česta pojava u svakodnevnoj komunikaciji. Ona je sredstvo konceptualizacije - način na koji shvatamo svet i izražavamo se. U poslednjih nekoliko decenija, istraživanja u okviru kognitivne lingvistike bavila su se ovakvim temama, najčešće zasnovana na okvirima koje su postavili Lejkof i Džonson. 


\subsection{Ciljevi i i hipoteze}

Prvi cilj ovog rada je poređenje metaforičke konceptualizacije LJUBAVI u tekstovima pesama srpskih i američkih izvođača na njihovim maternjim jezicima (po 37 pesama Tejlor Svift, Džona Ledženda, Aleksandre Radović i Željka Joksimovića). Poznato je da su mnoge pojmovne metafore univerzalne širom sveta, te je korisno uporediti ova dva jezika i kulture. Drugi cilj jeste poređenje iste pojave na osnovu pola izvođača jer ova varijabla ume biti relevantna $u$ jezičkim istraživanjima. Bavimo se pojmom (romantične) LJUBAVI zato što se ona pripisuje gotovo svakom ljudskom biću, a kako su razlike između ljudi potencijalno beskonačne, zanimljivo je istražiti da li uprkos tome postoje tendencije ka istim metaforama - još više kad se uzmu u obzir kulturološke i razlike između polova. Odabrani korpus je pop muzika pošto je ljubav vrlo česta tema u tom žanru, što je slučaj i sa diskografijom odabranih pevača.

Glavna hipoteza, zasnovana na prethodnim istraživanjima na ovu temu, jeste da će izvorni domeni uočeni u dva jezika biti slični, kao i da će to najčešće biti PUTOVANJE, VATRA, RAT, BOL. Pretpostavka je da će biti blagih razlika između dva pola, kako u smislu učestalosti izvornih domena tako i $u$ smislu konvencionalnosti metafore.

\subsection{Prethodna istraživanja}

Pojmovna metafora predmet je mnogih istraživanja, uglavnom sa korpusom vezanim za određenu oblast. Kako se ovaj rad bavi metaforom LJUBAVI u pop muzici, mnoga od prikazanih prethodnih istraživanja odnose se upravo na muziku.

Tisari (Tissari 2001) nudi dijahronu analizu pojmovne metafore LJUBAVI u tekstovima pisanim od 15 . veka naovamo, zaključivši da ima promena (recimo, u modernom engleskom ima manje metafora povezanih sa poljoprivredom), ali metafore su uglavnom ostale postojane, odražavajući ljudska iskustva na osnovu vremenskih, mesnih i senzornih domena. Gavelin (2015) piše o metafori LJUBAVI uočenoj na dva albuma pevačice Maraje Keri. To je dijahrono proučavanje koje utrvrđuje da li se upotreba pomenute metafore promenila 24 godine nakon početka karijere ove pevačice. Rezultati pokazuju da vremenska razlika nije imala velik uticaj - izvorni domeni uglavnom su ostali nepromenjeni; jedino je učestalost metafore veća, što može biti rezultat raznih faktora. Najčešći domeni su PREDMET i PUTOVANJE. Džohanson (Johansson 2016) analizira pojmovne metafore LJUBAVI, ŽIVOTA i SMRTI u tekstovima pesama Lenarda Koena, a uočeni izvorni domeni kad 
je u pitanju LJUBAV jesu FIZIČKA SILA, PACIJENT, LUDILO, MAGIJA, RAT i PUTOVANJE.

Istraživanja pojmovne metafore LJUBAVI kod nas nisu naročito brojna. Klikovac (2004) proučava čoveka kao metaforičkog SADRŽATELJA emocija, između ostalog i ljubavi. Rezultati pokazuju da LJUBAV, kao i druga osećanja, može biti prototipičan SADRŽANI OBJEKAT emocionalnog prostora. Ista autorka (Klikovac 2007) izučava rečničke definicije ljubavi i primere iz elektronskog korpusa, navodeći niz uočenih izvornih domena: VATRA, SKRIVENI PREDMET, SADRŽATELJ, SVETLOST, BOLEST i dr. Prodanović-Stankić (2009) razmatra pojmovnu metaforu i metonimiju lekseme srce u srpskom jeziku, što je često povezano sa LJUBAVI jer, kako autorka navodi, SRCE je najčešće konceptualizovano kao POSUDA EMOCIJA I RASPOLOŽENJA, što obuhvata i ljubav. $\mathrm{S}$ tim u vezi, česta je metafora LJUBAV JE VATRA, OBJEKAT, BILJKA KOJA JE NIKLA U NAŠEM SRCU i druge metafore zasnovane na metonimiji. Dragićević (2010) analizira pojmovne metafore LJUBAVI kroz asocijativnu metodu, a neki od odgovora ispitanika na stimulus ljubav jesu MUZIKA, CVET, POEZIJA, VATRA, NEBO. Šulović \& Drobnjak (2013) porede ovu metaforu na srpskom, španskom i francuskom, a rezultati pokazuju da je konceptualizacija LJUBAVI realizovana vrlo slično u datim jezicima (najčešće preko domena PUTOVANJE, VATRA, BOLEST, LUDILO, ZAVISNOST i dr.). Predmet rada čiji su autori Đurić \& Ćirić (2014) je metaforička i metonimijska konceptualizacija LJUBAVI u tekstovima srpskih turbofolk pesama ženskih izvođača. Rezultati otkrivaju upotrebu izvornih domena koji su česti, prvenstveno u anglosaksonskoj literaturi (VATRA, HRANA, FIZIČKA SILA, LUDILO, MAGIJA i dr.), ali uočeni su i neki manje česti domeni. Zaključeno je da ubedljivo preovlađuju domeni VIŠA SILA i FIZIČKA/SOCIJALNA PODREĐENOST OBJEKTU LJUBAVI. Izgarjan \& Prodanović-Stankić (2015) analiziraju način na koji studenti anglistike na drugoj i četvrtoj godini studija razumeju metaforu LJUBAVI u poeziji i popularnim pesmama. Rezultati pokazuju da pol studenata nije značajno uticao na rezultate koliko je to bio slučaj s njihovim godinama. Naime, stariji učesnici zabeležili su bolje rezultate, a veruje se da je to zato što su imali više časova književnosti od mlađih učesnika. Perović \& Vuković-Stamatović (2021) izučavaju konceptualizaciju LJUBAVI kod crnogorskih studenata, čiji je zadatak bio da dopune rečenicu „Ljubav je...“. Neki od najčešćih odgovora su POVEZANOST, FIZIČKA BOL, HRANA, ELEMENT IZ PRIRODE i dr. Primećeno je da su ženski ispitanici ponudili raznovrsnije metafore, kao i da su njihovi primeri sadržali više pozitivnih aspekata ljubavi u poređenju sa muškim ispitanicima. 


\subsection{Korpus i metodologija}

U ovom radu izučavamo tekstove pesama pop muzike na engleskom i srpskom jeziku čija je tema ljubav, i koji, pretpostavljamo, sadrže leksičke realizacije metafore LJUBAVI. Njih potom povezujemo sa pojmovnim metaforama. To nisu samo stihovi sa samom rečju ljubav nego i svi oni gde se peva o romantičnoj ljubavi, povezanim elementima i ljubavnoj vezi.

Korpus čini 148 pesama: po 37 pesama Tejlor Svift, Džona Ledženda, Aleksandre Radović i Željka Joksimovića. Ovi pevači odabrani su zbog opažanja da je ljubav dominantna tema u njihovoj muzici. Nakon pažljivog čitanja tekstova, svi relevantni primeri izdvojeni su i klasifikovani prema izvornim domenima. Izračunat je ukupan broj različitih izvornih domena kod svakog pevača i broj primera unutar svakog domena, te se putem jednostavne matematičke formule (broj primera unutar domena podeljen ukupnim brojem primera i pomnožen sa 100) dolazi do procentualne zastupljenosti određenog domena u tekstovima svakog izvođača.

$\mathrm{U}$ analizi, najpre je prikazana lista domena kod svakog izvođača ponaosob, od najčešćeg ka najmanje čestom. Sledi poređenje konceptualizacije LJUBAVI u pesmama na dva jezika, a zatim i na osnovu pola. Primeri uočeni u engleskom propraćeni su prevodom na srpski. Uz svaki primer dati su inicijali izvođača, kao i broj pesme prema spisku priloženom na kraju rada. Kako je broj primera previše velik da bi se svi naveli, odabrano je nekoliko reprezentativnih stihova za svaku kategoriju. Nazivi domena sa udelom manjim od 5\% nisu propraćeni primerima.

\section{TEORIJSKI OKVIR}

Temelj od kog treba krenuti je kognitivna semantika, odnosno pogled na jezik kao sastavni deo ljudskih kognitivnih sposobnosti. Ovaj pristup nastao je sedamdesetih godina prošlog veka, a doživeo je veće interesovanje i razvoj deceniju kasnije. Naš fokus je jedan od glavnih elemenata kognitivne semantike pojmovna metafora. Pojam su uveli lingvista Džordž Lejkof i filozof Mark Džonson u knjizi Metaphors We Live By (1980). Autori su opisali pojmovnu metaforu kao sastavni deo umnog procesa u kojem čovek sebi predstavlja stvarnost. Oni su primetili da se metafore ne koriste samo za isticanje sličnosti između dva elementa već čitava dva pojmovna domena i to na osnovu određenih znanja i iskustava. Kako Kevečeš (Kövecses 2010: 4) objašnjava, jedan pojam se preslikava iz konkretnijeg, tzv. izvornog domena na manje poznat, apstraktniji, 
tzv. ciljni domen. Pojmovna metafora najčešće se predstavlja na sledeći način: CILJNI DOMEN JE IZVORNI DOMEN. Na primer, metafora LJUBAV JE PUTOVANJE (LOVE IS A JOURNEY) vrlo je česta, pri čemu se ciljni domen LJUBAVI konceptualizuje koristeći pojam PUTOVANJA, koji je bliži našem iskustvu. Po toj logici, ljubavna veza je prevozno sredstvo, osobe u vezi su putnici, njihovi zajednički ciljevi su odredište, pređeni put je postignut napredak, a neslaganja su prepreke na putu. Kada je u pitanju ljubav kao ciljni domen, Lejkof i Džonson navode nekoliko potencijalnih izvornih domena: PUTOVANJE, FIZIČKA SILA, MAGIJA, PACIJENT, LUDILO, RAT. To su konvencionalne metafore, sa visokim stepenom ustaljenosti, a postoje i one nekonvencionalne, koje nisu ustaljene i nude novo viđenje pojmova. Evans (2007) dodaje da su ovakva preslikavanja uvek jednosmerna - od izvornog domena ka ciljnom, od pojmova iz svakodnevnog iskustva (često čulno-motorni pojmovi) ka apstraktnom.

Kako ističu prethodno pomenuti autori (Lakoff \& Johnson 1980/2003, Kövecses 2010, prema Filipović-Kovačević (2013), koja navodi i dodatne primere), treba naglasiti da pojmovne metafore uključuju samo neke aspekte dva domena, a koji od aspekata se upotrebljava, zavisi od toga šta govornik želi da istakne. Na taj način u ciljnom domenu dolazi do tzv. metaforičkog isticanja, a u izvornom domenu do metaforičkog iskorišćavanja, pri čemu se neaktivirani aspekti potiskuju. Važno je reći i da se određene, ali ne sve, pojmovne metafore smatraju univerzalnim, što potvrđuje njihovo prisustvo u jezicima koji nisu srodni (v. Wierzbicka \& Jamrozik 1988, Kövecses 1988, 2006, Šulović \& Drobnjak 2013).

U literaturi se spominje i pojmovna metonimija, pojava kad se deo jednog domena koristi da se uputi na čitav domen (Barcelona 1997) - na primer, INSTITUCIJA UMESTO OSOBE (recimo, Bela kuća u značenju predsednika SAD-a). Dakle, i pojmovna metonimija uključuje dva pojma - jedan konkretniji (sredstvo), koji obezbeđuje pojmovni/mentalni pristup drugom, apstraktnijem (ciljnom) pojmu, ali, u ovom slučaju, oba pojma su u jednom pojmovnom domenu.

Kako je doživljavanje osećanja često propraćeno određenim fizičkim reakcijama organizma, čovek može konceptualizovati ta osećanja pomoću takvih propratnih reakcija. Kao što su primetili Đurić \& Ćirić (2014), takva veza je metonimijska. Tako se, na primer, za pojmovnu metaforu LJUBAV JE SMANJENA SPOSOBNOST DISANJA može reći da je metonimijski motivisana.

$\mathrm{Na}$ osnovu ovih definicija, jasno je da pojmovna metafora i metonimija dele dosta sličnosti kao kognitivni mehanizmi koji uključuju proces preslikavanja. Katkad ih je teško razgraničiti jer nije lako odrediti da li se preslikavanje odigralo 
unutar jednog domena ili sa izvornog na ciljni. Tejlor (Taylor 1995) tvrdi da je u osnovi svake pojmovne metafore metonimija, dok Raden (Radden 2003) vidi ove dve pojave kao dva kraja jednog kontinuuma, te su slučajevi kad su metonimija i metafora isprepletene u zoni između ta dva kraja. U literaturi se može naći i termin metaftonimija (Goossens 1990), pojava kad su metafora i metonimija združene. Dakle, za precizno razgraničavanje ova dva načina razmišljanja potreban je kontekst koji pruža dovoljno podataka.

\section{ANALIZA KORPUSA}

Analiza ranije opisanog korpusa organizovana je na sledeći način: metafore u jezičkom obliku koje opisuju ljubavnu emociju i druge elemente tog pojma povezane su sa pojmovnim metaforama kod svakog izvođača ponaosob. Izvorni domeni sa zastupljenošću manjom od 5\% jesu navedeni, ali nisu propraćeni primerima. Nakon prikaza reprezentativnih primera, sledi analiza metafore LJUBAVI na osnovu dva jezika, a potom i na osnovu dva pola.

\subsection{Konceptualizacija ljubavi u odabranim pesmama}

\subsubsection{Konceptualizacija ljubavi u pesmama Tejlor Svift}

U odabranim stihovima pevačice Tejlor Svift pronađene su 123 leksikalizovane metafore LJUBAVI povezane sa 26 različitih pojmovnih domena.

Najfrekventniji domeni jesu BOL/BOLEST i (PISANA) PRIČA, svaki sa po 10 primera. Za početak, možemo primetiti da domen BOL/BOLEST (primeri 1-4) najčešće podrazumeva metonimijski motivisanu metaforu LJUBAV JE SMANJENA SPOSOBNOST DISANJA, što se tipično javlja kao rezultat odsustva objekta ljubavi. Kod metafore LJUBAV JE (PISANA) PRIČA (5-8), OSOBE U VEZI uglavnom se vide kao AUTORI/KNJIŽEVNI LIKOVI, DEŠAVANJA U VEZI kao ISPISIVANJE STRANICA i RASKID VEZE Kao KRAJ PRIČE.

1) It'll leave you breathless or with a nasty scar (TS5)

(Ostaviće te bez daha ili sa gadnim ožiljkom)

2) If I bleed you'll be the last to know (TS10)

(Ako budem krvarila, ti ćeš poslednji saznati)

3) Can't breathe whenever you're gone (TS18)

(Ne mogu da dišem kad god nisi tu)

4) We fall in love 'til it hurts or bleeds (TS32)

(Zaljubljujemo se dok ne počne da boli ili krvari) 
5) We were a fresh page on the desk, filling in the blanks as we go (TS9)

Bili smo nova stranica na stolu, popunjavajući praznine usput)

6) If the story's over, why am I still writing pages? (TS13)

(Ako je priča gotova, zašto i dalje ispisujem stranice?)

7) The story of us looks a lot like a tragedy now (TS35)

(Priča o nama čini se kao tragedija sada)

8) Lately I don't even know what page you're on (TS35)

(U poslednje vreme ne znam ni na kojoj si stranici)

Sledeći domen je IGRA/KOCKA, sa 9 primera. Ovaj pojam uglavnom sa sobom nosi negativno viđenje da je ljubav neiskrena ili se pak igra posmatra kao pokušaj osvajanja objekta ljubavi.

9) 'Cause you know I love the players / And you love the game (TS5) (Jer znaš da volim igrače / A ti voliš igru)

10) Back when we were card sharks, playing games (TS9)

(Ranije kad smo bili varalice, igrali igre)

11) I lived in your chess game / But you changed the rules every day (TS12)

(Živela sam u tvojoj igri šaha / Ali ti si menjao pravila svaki dan)

12) It's poker, he can't see it in my face / But I'm about to play my Ace (TS28)

(To je poker, on ne vidi to na mom licu / Ali spremam se da bacim asa)

Izvorni domen PUTOVANJE/VOŽNJA sledeći je sa 8 primera. Kao što je očekivano, OSOBE U VEZI vide se kao PUTNICI, PROBLEMI U VEZI kao NEZGODE NA PUTU ili GUBITAK ORIJENTACIJE, a ZAJEDNIČKI CILJEVI kao ODREDIŠTE.

13) Every little bump in the road I tried to swerve (TS6)

(Svaku malu neravninu na putu pokušala sam da zaobiđem )

14) We wait for trains that just aren't coming (TS28)

(Čekamo vozove koji neće doći)

15) I watch us go 'round and 'round each time (TS34)

(Gledam nas kako idemo ukrug svaki put)

Po 7 primera uočeno je kod domena VATRA/PLAMEN (16-18) i RAT/BORBA (19-21). LJUBAV se uglavnom vidi kao VREDNA NAGRADA, ali i 
IZGUBLJENI RAT kad je neuspešna. Dok se u različitim korpusima domen VATRA/PLAMEN često pokazao i kao simbol STRASTI I SNAŽNIH OSEĆANJA, u ovom radu taj pojam tipično predstavlja KRAJ LJUBAVI.

16) I'm the one who burned us down (TS1)

(Ja sam ta koja nas je spalila)

17) I took your matches before fire could catch me (TS12)

(Oduzela sam ti šibice pre nego što je vatra stigla da me zahvati)

18) Love's a fragile little flame / It could burn out (TS22)

Ljubav je krhki, mali plamen / Mogla bi da se ugasi)

19) Hung my head as I lost the war (TS7)

(Pognula sam glavu jer sam izgubila rat)

20) I wish we could go back and remember what we were fighting for (TS24)

(Volela bih da možemo da se vratimo i setimo se za šta smo se borili)

21) This is the worthwhile fight (TS32)

(Ovo je borba vredna truda)

Posmatranje LJUBAVI kao BOGA/RELIGIJE (22-25) otkriveno je u 6 primera, od kojih su čak 4 iz pesme False God (Lažni bog). Isti broj primera ima izvorni domen VREMENSKE PRILIKE (25-27) i svi oni PROBLEME U VEZI prikazuju kao KIŠU i OLUJU.

22) Even if it's a false god / We'd still worship this love (TS16)

(Čak i da je lažni bog / Mi bismo obožavali ovu ljubav)

23) Religion's in your lips (TS16)

(Religija je na tvojim usnama)

24) No rules in breakable heaven (TS10)

(Nema pravila u lomljivom raju)

25) Screaming, crying, perfect storms (TS5)

(Vriska, plakanje, savršene oluje)

26) What a rainy ending given to a perfect day (TS8)

(Kakav kišovit kraj posle savršenog dana)

27) It rains when you're here and it rains when you're gone (TS17)

(Pada kiša i kad si tu i kad odeš)

Domeni sa udelom manjim od 5\% jesu: DROGA/ZAVISNOST, GRAĐEVINA, LUDILO/MENTALNI POREMEĆAJ, MAGIJA, PREDMET (po 5 primera), 
GREŠKA/NEUSPEH, OSOBA, SVETLOST, UBICA, VODA (po 4 primera), POREMEĆAJ OSEĆAJA ZA VREME, SRAM/PONIŽENJE, TAJNA (po 3 primera), SAN (2 primera), BILJKA, IZLEČITELJ, OSEĆAJ KRIVICE, PIĆE (po 1 primer). Očigledno je da su tekstovi pesama pevačice Tejlor Svift bogati metaforama LJUBAVI.

\subsubsection{Konceptualizacija ljubavi u pesmama Džona Ledženda}

U odabranim tekstovima pesama Džona Ledženda uočena su 23 izvorna domena sa 81 primerom leksikalizovane metafore LJUBAVI. Njihova frekventnost varira, te je broj primera $u$ daljem tekstu prilagođen tome.

Izvorni domen sa najvećim brojem primera (10) jeste PUTOVANJE/VOŽNJA. Preslikavanja su vrlo tipična - OSOBE U VEZI SU PUTNICI, ZAJEDNIČKI CILJEVI SU ODREDIŠTE i sl.

28) Let me sail away with you (JL8)

(Pusti me da otplovim s tobom)

29) I don't know where the road leads (JL29)

(Ne znam kud vodi ovaj put)

30) Wherever you're going / I'm going too (JL34)

(Kud god ti ideš / Idem i ja)

31) I swear you're the only one I'd take on this ride (JL37)

(Kunem se, ti si jedina koju bih poveo u ovu vožnju)

Sledeći izvorni domeni beleže po 9 primera. Kod domena IGRA/KOCKA (32-35), česti motivi su kartaške igre, pravila i okušavanje sreće. Metafora LJUBAV JE LUDILO/MENTALNI POREMEĆAJ (36-39) u najvećem broju slučajeva sadrži samu reč crazy (lud).

32) Cards on the table, we're both showing hearts (JL2)

(Karte na sto, oboje pokazujemo srca)

33) Imma break the rules, gonna change the game (JL14)

(Prekršiću pravila, promeniću igru)

34) Now they bet on our game (JL23)

(Sad se klade na našu igru)

35) You got me talking crazy (JL1)

(Zbog tebe pričam ludosti)

36) To the edge of reason / Go lose your mind with me (JL2)

(Do granice razuma / Izgubi razum sa mnom)

37) Our love's an asylum / Where we go, go, go, go crazy... (JL2)

(Naša ljubav je umobolnica / U kojoj postajemo ludi...) 
Treći najčešći domen je BOL/BOLEST, sa 7 primera. Pri tome, česta su metonimijski motivisana preslikavanja. To su uglavnom SMANJENA SPOSOBNOST DISANJA, VRTOGLAVICA, KRVARENJE.

38) Can't breathe when you're moving like that (JL1)

(Ne mogu da dišem kad se krećeš tako)

39) My heart bleeding (JL6)

(Moje srce krvari)

40) There'll be heartaches and pain (JL30)

(Biće bola u srcu i patnje)

Kod domena Plamen/VATRA uočeno je 6 primera. Pri tome, VATRA i OPEKOTINE uglavnom predstavljaju SNAŽNA OSEĆANJA, ali i POVREĐENA OSEĆANJA.

41) Though you've been burned / You still return (JL12)

(Iako si bivala opečena / I dalje se vraćaš)

42) No, I won't let the blue flame die (JL31)

(Ne, neću dopustiti da se plavi plamen ugasi)

43) You set me on fire (JL37)

(Ti si me zapalila)

Ukupno 5 primera uočeno je kod metafore LJUBAV JE PREDMET. Pri tome, LJUBAV se konceptualizuje kao nešto lomljivo ili nešto što može da se dâ/pokloni.

44) Fragile is my love (JL7)

(Krhka je moja ljubav)

45) Give me your emotion, your heart's devotion (JL12)

(Daj mi svoju emociju, posvećenost svog srca)

Ostali izvorni domeni imaju udeo manji od 5\%: GRAĐEVINA, MUZIKA, (PISANA) PRIČA, RAT/BORBA, VODA i VREMENSKE PRILIKE (po 3 primera), BOG/RELIGIJA, DROGA/ZAVISNOST, GUBITAK KONTROLE, MIR, SVETLOST i UBICA (po 2 primera) i MAGIJA, OSOBA, POREMEĆAJ OSEĆAJA ZA VREME, SAN i TAJNA (po 1 primer). Može se reći da je prisutnost metafore LJUBAVI kod ovog izvođača visoka, ali mnogi domeni bili su prilično nezastupljeni. 


\subsubsection{Konceptualizacija ljubavi u pesmama Aleksandre Radović}

U odabranim stihovima Aleksandre Radović uočen je 21 izvorni domen sa 75 primera metafore LJUBAVI. Posle onog najdominantnijeg, brojnost primera kod ostalih domena ne oscilira mnogo.

Daleko najčešća metafora, sa 13 primera, jeste LJUBAV JE BOL/BOLEST/FIZIČKI POREMEĆAJ. Većina stihova sadrži reč bol, čiji je izvor sama emocija ljubavi ili objekat ljubavi. Metafora LJUBAV JE SMANJENA SPOSOBNOST DISANJA, koja se uglavnom pokazala čestom u ovoj kategoriji, nije uočena.

46) Ostaćeš zauvek moje mesto za bol (AR3)

47) Podsetnik za bol je uvek tu (AR9)

48) Opet rani me u stare rane (AR13)

49) Hronično sam umorna / Od tebe, mene, nje i ko zna čega (AR17)

Drugi najprisutniji domen je SRAM/PONIŽENJE sa 7 primera. U tom smislu, LJUBAV se često vidi KAO GUBITAK PONOSA i PODREĐENOST OBJEKTU LJUBAVI.

50) Odavno ja sam na brodu budala otplovila (AR7)

51) Gde mi je ponos, pitam se... (AR23)

52) Čekam u redu za mrvu ljubavi ponizno... (AR34)

Treći po frekventnosti je domen RAT/BORBA sa 6 primera, od čega su čak 4 uočena u pesmi Bori se. Stihovi najčešće prikazuju OSOBE U VEZI kao RATNIKE, a KRAJ VEZE kao IZGUBLJENU BITKU.

53) Ova bitka samo je za dvoje / Žrtve dve u ratu ljubavi (AR6)

54) Bićeš iz mog srca jedini dezerter (AR13)

Ukupno 5 primera uočeno je kod izvornog domena (PISANA) PRIČA. Pri tome, česta je sama reč priča. Najprisutnija je metafora KRAJ LJUBAVNE VEZE JE KRAJ PRIČE.

55) Na svakoj ljubavi ja napišem „ne” (AR4)

56) Ja iz ove priče izlazim (AR19)

Izvorni domeni sa udelom manjim od 5\% su: GREŠKA/NEUSPEH, LUDILO/MENTALNI POREMEĆAJ, OSOBA, PUTOVANJE/VOŽNJA, RAZLOG ZA ŽIVOT, VREMENSKE PRILIKE (po 4 primera), IGRA/KOCKA, POREMEĆAJ OSEĆAJA ZA VREME, SAN (po 3 primera), GRAĐEVINA, PLAMEN/VATRA, TAJNA (po 2 primera), i 
DROGA/ZAVISNOST, IZLEČITELJ, OSEĆAJ KRIVICE, PIĆE (po 1 primer). Evidentno je da je lista domena raznovrsna, ali neki od njih imaju značajno veću zastupljenost.

\subsubsection{Konceptualizacija ljubavi u pesmama Željka Joksimovića}

U tekstovima pesama Željka Joksimovića otkriven je 21 izvorni domen i 55 relevantnih primera. Nakon najčešćeg domena, učestalost prilično naglo opada i velik je broj domena sa vrlo malim brojem primera.

Daleko najzastupljeniji je domen BOL/BOLEST, koji je reprezentovan sa 13 primera. Najčešće se određeni postupak objekta ljubavi ocenjen kao negativan konceptualizuje kao izvor bola. Metafora LJUBAV JE SMANJENA SPOSOBNOST DISANJA, koja se uglavnom pokazala čestom, nije primećena.

57) Bolujem kad smo zajedno (ŽJ15)

58) Samo moja ti jedina si bol (ŽJ19)

59) Zbog tebe ću skroz da se razbolim / A ljubav je danas bolest retka (ŽJ23)

60) Grudi mi tesne, želje mi pobesne / Treba mi anestezija (ŽJ34)

Sa 7 primera, izvorni domen LUDILO/MENTALNI POREMEĆAJ drugi je najzastupljeniji. U ovim stihovima, najčešće se LJUBAVNI ZANOS konceptualizuje kao GUBITAK RAZUMA.

61) Drska ženo plava, poludela mi glava (ŽJ9)

62) I toliko pamet pomera (ŽJ10)

63) Hoću da ljubim, skroz da poludim (ŽJ30)

Domen PLAMEN/VATRA ima 4 primera. Pri tome, PLAMEN i VATRA uglavnom se vide kao POTENCIJALNA OPASNOST. Takođe, ovaj domen može da predstavlja i SNAŽNA OSEĆANJA.

64) Nisam te terao vatru da diraš (ŽJ3)

65) Zapali se srce (ŽJ20)

Metafora LJUBAV JE PUTOVANJE/VOŽNJA, sa 3 primera, ponovo uključuje očekivana preslikavanja - OSOBE U VEZI SU PUTNICI, NESLAGANJA U VEZI SU NEZGODE NA PUTU/GUBITAK ORIJENTACIJE i sl.

66) Ova ljubav samo moj je brodolom (ŽJ22) 
Izvorni domeni sa udelom manjim od 5\% jesu: GRAĐEVINA, IZLEČITELJ, PREDMET, UBICA, VODA, VREMENSKE PRILIKE (po 2 primera) i DROGA/ZAVISNOST, MIR, MUZIKA, OSOBA, POREMEĆAJ OSEĆAJA ZA VREME, (PISANA) PRIČA, RAT/BORBA, RAZLOG ZA ŽIVOT, TAJNA (po 1 primer). Iako je i kod ovog izvođača broj domena velik, primeri su značajno manje brojni.

\subsection{Englesko-srpska i rodno zasnovana kontrastivna analiza}

Ukupan broj primera na oba jezika u ovoj analizi pojmovne metafore LJUBAVI je 334: 123 kod Tejlor Svift, 81 kod Džona Ledženda, 75 kod Aleksandre Radović i 55 kod Željka Joksimovića.

Potvrđeno je očekivanje da se metafora LJUBAVI javlja u sličnim/istim oblicima unutar različitih kultura i jezika jer je veliki broj identičnih izvornih domena uočen u pesmama na engleskom i srpskom. Među najzastupljenijim domenima $\mathrm{u}$ korpusu na oba jezika jesu BOL/BOLEST, IGRA/KOCKA, LUDILO/MENTALNI POREMEĆAJ, PUTOVANJE, pri čemu su preslikavanja između domena takođe vrlo slična. Dakle, uočene pojmovne metafore su konvencionalne. Neke od metafora nisu primećene ni u jednom od prethodnih istraživanja ni na engleskom ni na sprskom jeziku, zbog čega ih možemo smatrati nekonvencionalnim. Takve su metafore LJUBAV JE POREMEĆAJ OSEĆAJA ZA VREME (vreme koje teče usporeno/ubrzano, vraćanje vremena unazad i sl), KRIVICA i MIR. Zanimljivo je primetiti i da se kod metafore LJUBAV JE BOL/BOLEST $\mathrm{u}$ engleskom vrlo često pojavljivala metonimijska konceptualizacija LJUBAVI kao SMANJENE SPOSOBNOSTI DISANJA, što u srpskom nije bio slučaj. I drugi oblici ove metafore mogu se smatrati metonimijski motivisanim, kao što su na primer: PATNJA USLED LJUBAVNOG NEUSPEHA JE FIZIČKA BOL.

U pesmama na engleskom zabeležen je daleko veći broj primera metafore LJUBAVI nego u srpskom (204 naspram 130). Od ukupnog broja izvornih domena (30), u tekstovima na engleskom jeziku pronađena su 4 domena koja nisu otkrivena na srpskom - BILJKA, BOG/RELIGIJA, MAGIJA i SVETLOST. Ovi domeni nisu se pokazali kao česti ni u pesmama američkih pevača (svi sa udelom manjim od 4\%), ali ipak su prisutni. Izvorni domeni sa primetno većom zastupljenošću u pesmama na engleskom spram onih na srpskom jesu i DROGA/ZAVISNOST i PREDMET. To bi mogao biti pokazatelj da se u anglofonoj kulturi ljubav ponekad vidi kao nešto prolazno (biljke imaju ograničenu životnu dob, predmeti se lome/gube itd.) ili pak nešto potencijalno neuhvatljivo/neobjašnjivo (božanstvo, čarolija, svetlost). Metafora uočena samo u pesmama na srpskom je LJUBAV JE RAZLOG ZA ŽIVOT. Metafora LJUBAV JE IZLEČITELJ zastupljenija je u tekstovima 
na srpskom nego na engleskom, iako nije preterano prisutna ni u srpskim pesmama.

Dakle, pojmovna metafora LJUBAVI u tekstovima pop muzike na srpskom i engleskom široko je rasprostranjena i preslikavanja iz raznih izvornih domena u ciljni domen dele mnogo više sličnosti nego razlika. Time je potvrđena jedna od hipoteza navedenih u uvodu ovog rada, kao i rezultati prethodnih istraživanja na sličnu temu.

Što se tiče pola izvođača, najzastupljeniji izvorni domen kod oba pola jeste BOL/BOLEST. Kod žena, sledeći najčešći domen je (PISANA) PRIČA, kao i IGRA/KOCKA i VREMENSKE PRILIKE. Kod muških izvođača, drugi najzastupljeniji domen je LUDILO/MENTALNI POREMEĆAJ, kao i IGRA/KOCKA, a sa nešto nižim udelom i PLAMEN/VATRA i PREDMET. Preslikavanja iz određenog izvornog domena u ciljni domen LJUBAVI dele mnoge sličnosti. Određeni domeni (iako neki od njih imaju izuzetno mali udeo) zapaženi su samo kod žena - BILJKA, GREŠKA/NEUSPEH, KRIVICA, PIĆE, SRAM/PONIŽENJE. S druge strane, izvorni domeni uočeni samo kod muškaraca jesu GUBITAK KONTROLE, MIR, MUZIKA. Domeni primetno zastupljeniji kod žena su i (PISANA) PRIČA i RAT/BORBA, ali i OSOBA, POREMEĆAJ OSEĆAJA ZA VREME, SAN. Domeni koji su mnogo češći kod muških izvođača su IGRA/KOCKA, LUDILO/MENTALNI POREMEĆAJ i PUTOVANJE/VOŽNJA. To bi mogao biti znak da žene ponekad imaju ozbiljnije i tragičnije viđenje LJUBAVI, naročito kada je ona neuspešna. Ovakav zaključak podržavaju i rezultati istraživanja Ćirić \& Đurić (2014), u kom se pokazalo da su izvorni domeni VIŠA SILA (LUDILO, BOLEST, PRIRODNA SILA) i SOCIJALNA/DRUŠTVENA PODREĐENOST OBJEKTU LJUBAVI najčešći domeni u turbo-folk pesmama srpskih pevačica. Takođe, naši rezultati idu u prilog istraživanju Perović \& Vuković-Stamatović (2021), čiji nalazi govore da su crnogorske studentkinje koristile raznovrsnije metafore LJUBAVI nego što su to činili studenti, kao i da su ženski ispitanici videli ljubav na pozitivniji način.

Od ukupnog broja primera u ovom radu, 198 se odnosi na ženske i 136 na muške izvođače, ali, kao što je već istaknuto, najveći broj primera sadrže pesme Tejlor Svift (čak 123). Iako Džon Ledžend i Aleksandra Radović imaju sličan rezultat u tom smislu, primećujemo da u tekstovima srpske pevačice ima više slučajeva pomenute metafore nego kod srpskog pevača (75 naspram 55), te se može reći da je pojmovna metafora LJUBAVI češća pojava kod pevačica. Svi ovi nalazi potvrđuju i pretpostavku da će biti blagih razlika u odnosu na pol izvođača. Naravno, potrebna su dodatna istraživanja šireg obima kako bismo mogli sa većom sigurnošću donositi zaključke. 


\section{ZAKLJUČAK}

Predmet ovog rada jeste metaforička konceptualizacija LJUBAVI u tekstovima pesama dva američka i dva srpska muzička izvođača na engleskom i srpskom. Jedan od izvođača unutar obe jezičke grupe je ženskog a jedan muškog pola. Kako se smatra da su pojmovne metafore kao sredstvo poimanja sveta oko nas jednim delom univerzalne širom kultura i jezika, ovo istraživanje usredsređuje se na razlike koje proističu iz dva jezika na kojima se peva kao i iz pola izvođača.

Rezultati pokazuju da se LJUBAV zaista konceptualizuje na sličan način u američkoj i srpskoj pop muzici, ali postoje i određene razlike. Broj primera bio je veći u pesmama na engleskom, a tu su otkrivena i četiri izvorna domena koja nisu uočena u srpskom (BILJKA, BOG/RELIGIJA, MAGIJA, SVETLOST), dok je svega jedan domen (RAZLOG ZA ŽIVOT) prisutan samo u srpskom delu korpusa. Iako je u oba jezika najčešći domen bio BOL/BOLEST, metonimijski motivisana konceptualizacija LJUBAVI kao SMANJENE SPOSOBNOSTI DISANJA nije zabeležena u srpskim pesama.

Što se tiče analize na osnovu pola, najznačajniji nalaz je da su izvorni domeni (PISANA) PRIČA, RAT/BORBA, OSOBA, POREMEĆAJ OSEĆAJA ZA VREME, SAN zabeležili više primera kod ženskih nego muških izvođača. Domeni IGRA/KOCKA, LUDILO/MENTALNI POREMEĆAJ, PUTOVANJE/VOŽNJA pokazali su se mnogo češćim kod muškaraca. Domeni uočeni jedino kod žena su BILJKA, GREŠKA/NEUSPEH, KRIVICA, PIĆE, SRAM/PONIŽENJE, a samo kod muškaraca GUBITAK KONTROLE, MIR, MUZIKA.

Rezultati potvrđuju hipotezu da nema brojnih razlika između tekstova na engleskom i srpskom. Rezultati takođe potrvrđuju da su razlike na osnovu pola izvođača vrlo blage. Dodatna istraživanja koja uključuju konzumente pop muzike bila bi korisna kako bi se stekao bolji uvid u konceptualizaciju LJUBAVI u tekstovima pesama jer pojmovne metafore mogu biti donekle subjektivne.

\section{IZVORI - SPISAK PESAMA}

Dostupno putem linka: https://rb.gy/jowzju

\section{LITERATURA}

Barcelona, Antonio. 1997. "Clarifying and applying the notions of metaphor and metonymy within cognitive linguistics". Atlantis 19: 121-48. 
Dragićević, Rajna. 2010. Leksikologija srpskog jezika. Beograd: Zavod za udžbenike.

Đurić, Ljubica \& Ćirić, Mladen. 2014. „Metaforička i metonimijska konceptualizacija ljubavi u tekstovima turbofolk pesama ženskih izvođača". U: Snežana Gudurić i Marija Stefanović (ur.), Jezici i kulture u vremenu i prostoru IV/1. Novi Sad: Filozofski fakultet: 55-67.

Evans, Vyvyan. 2007. A Glossary of Cognitive Linguistics. Edinburgh: Edinburgh University Press.

Filipović-Kovačević, Sonja. 2013. Implicirana značenja u reklamama na engleskom $i$ srpskom jeziku. Novi Sad: Filozofski fakultet. https://bit.ly/382BEOA (23.6.2020)

Gavelin, Emma. 2015. Conceptual metaphors: a diachronic study of LOVE metaphors in Mariah Carey's song lyrics. Umea: Umea University.

Goossens, Louis. 1990. "Metaphtonymy: the interaction of metaphor and metonymy in expressions for linguistic action". Cognitive Linguistics 1(3): 323-342.

Izgarjan, Aleksandra \& Prodanović-Stankić, Diana. 2015. Approaches to Metaphor: Cognitive, Translation and Literature Studies Perspective. Novi Sad: Filozofski fakultet.

Johansson, Anna. 2016. Conceptual Metaphors in Lyrics by Leonard Cohen. Umea: Umea University.

Klikovac, Duška. 2004. Metafore u mišljenju i jeziku. Beograd: Biblioteka XX vek / Knjižara Krug.

Klikovac, Duška. 2006. Semantika predloga: studija iz kognitivne lingvistike. Beograd: Filološki fakultet.

Kövecses, Zoltan. 1988. The language of love: The semantics of passion in conversational English. Bucknell University Press.

Kövecses, Zoltan. 2006. Language, Mind and Culture. A Practical Introduction. Oxford, New York: Oxford University Press.

Kövecses, Zoltan. 2010. "A new look at metaphorical creativity in cognitive linguistics". Cognitive Linguistics 21(4): 663-697.

Lakoff, George \& Johnson, Mark. 1980/2003. Metaphors We Live by. Chicago, London: The University of Chicago Press.

Perović, Slavica \& Vuković-Stamatović, Milica. 2021. "Universality and Cultural Variation in the Conceptualisation of Love via Metaphors, Metonymies and Cultural Scripts: The Case of Montenegrin“. Círculo de Lingüistica Aplicada a la Comunicación (85): 45-61. 
Prodanović-Stankić, Diana. 2009. „Pojmovna metonimija i metafora u značenjima lekseme srce u srpskom jeziku". Godišnjak Filozofskog fakulteta 34. Novi Sad, Filozofski fakultet: 77-87.

Radden, Günter. 2003. "How Metonymic are Metaphors?”. In: R. Dirven \& R. Pörings eds. Metaphor and Metonymy in Comparison and Contrast. Berlin, New York, Mouton de Gruyter: 407-434.

Šulović, Ksenija, Drobnjak, Dragana. 2013. „Koncept ljubavi u srpskom, francuskom i španskom jeziku". U: S. Gudurić i M. Stefanović (Ur.), Jezici i kulture u vremenu i prostoru II/2. Novi Sad, Filozofski fakultet: 139-147.

Taylor, John R. 1995. Linguistic Categorization. Oxford: Oxford University Press. Tissari, Heli. 2001. "Metaphors we love by: on the cognitive metaphors of love from the 15th century to the present". Studia Anglica Posnaniensia 36: 217-242.

Wierzbicka, Anna \& Jamrozik, Elżbieta. 1988. "L'amour, la colère, la joie, l'ennui. La sémantique des émotions dans une perspective transculturelle." Langages 89: 97-107. 
Milica M. Lukić

\section{CONCEPTUAL METAPHOR OF LOVE IN POP MUSIC LYRICS IN SERBIAN AND ENGLISH}

\section{Summary}

This paper examines the conceptual metaphor of LOVE in the lyrics found in the songs of four pop singers (one female and one male singer each in Serbian and English). As noted by Lakoff \& Johnson (1980/2003), conceptual metaphors reflect the way in which we see the world and express our opinions and emotions. The aim of this paper is to investigate if the conceptual metaphor of LOVE differs in songs in Serbian and English and if there are differences based on the singers' gender. We discovered that the most frequent source domains are PAIN/ILLNESS, GAME/GAMBLE, INSANITY/MENTAL DISORDER, and JOURNEY. The results also show that, although they are not too pronounced, there are certain differences in the conceptualization of LOVE based on the two languages mentioned and the two genders.

Key words: cognitive linguistics, conceptual metaphor, Serbian language, English language, conceptualization of love 